$$
\begin{array}{ll}
\text { Research Square } & \begin{array}{l}
\text { Preprints are preliminary reports that have not undergone peer review. } \\
\text { They should not be considered conclusive, used to inform clinical practice, } \\
\text { or referenced by the media as validated information. }
\end{array}
\end{array}
$$

\title{
Development, validation and implementation of a program to detect malnutrition with NRS-2002 screening tool in patients of the oncology and hematology service
}

Marta Pérez ( $\square$ marta_perez994@hotmail.com)

Universitat de Valencia https://orcid.org/0000-0003-0000-1938

José M Soriano

Universitat de Valencia

J Francisco Merino-Torres

Universitat de Valencia

\section{Research}

Keywords: Nutritional screening, hospital malnutrition, disease-related malnutrition, Nutritional Risk Screening 2002, oncology.

Posted Date: April 8th, 2020

DOI: https://doi.org/10.21203/rs.3.rs-20579/v1

License: @) (1) This work is licensed under a Creative Commons Attribution 4.0 International License. Read Full License 


\section{Abstract}

Background: Hospital malnutrition is an increasingly prevalent situation, which involves both an increase in health costs, a decrease in the life quality of those who suffer from it, and greater morbimortality. Nutritional screening is essential to detect malnutrition early and avoid these complications.

Methods: NRS-2002 was performed on all patients admitted to the oncohaematology service, followed by the complete nutritional assessment (VN) to check its validity, which is repeated weekly to determine the degree of malnutrition during the hospital stay. Data were summarized using mean (standard deviation) and median (1 st, 3rd quartile) for numerical variables, and absolute frequency (relative) for qualitative variables. To measure agreement between the two diagnoses, Cohen's Kappa was calculated for each visit. The level of association between the variables was measured using the Goodman and Kruskal measure.

Results: 573 patients were admitted to the oncohaematology service, of which: $34.4 \%$ malnutrition, $44.7 \%$ risk of malnutrition and $20.9 \%$ good nutritional condition, on admission to hospital according to the NRS-2002. In patients admitted for more than a week, NRS-2002 was performed weekly and found that, upon discharge, they suffered: $34.4 \%$ malnutrition, $50.8 \%$ risk of malnutrition and $14.76 \%$ good nutritional status; also $12.3 \%$ worsen their nutritional status, $68.9 \%$ maintain it and only $18.9 \%$ improve it. $78.8 \%$ of patients with longer admissions require a VN.

Conclusions: Our results suggest that the NRS-2002 is a simple and effective method for early malnutrition detection. It's important a nutritional monitoring during the hospitalization period, because the patients are susceptible to worsening of their nutritional status.

\section{Introduction}

The World Health Organization describes hospital malnutrition (HM) as a potential but preventable medical complication that influences the outcome of treatments. Hospitalized patients with malnutrition are more likely to prolong their hospital stay, as it is associated with an increased incidence of infections and delayed wound healing, among other consequences ${ }^{1}$. The European Association for Parenteral and Enteral Nutrition defines it as a state that leads to loss of muscle and fat mass, which can cause a decrease in mental and physical functional capacity, as well as a worse response to diseases, which is caused by a decrease in intake and/or assimilation of nutrients ${ }^{2}$. In addition, in cancer patients, immune suppression can usually be caused by malnutrition, surgical trauma, and the tumor's own immunosuppressive capacity ${ }^{3}$.

In the ill patient, malnutrition is more precisely called disease-related malnutrition (DRM) since both the disease and the relevant treatment are the main etiopathogenic factors ${ }^{4}$. DRM is damage caused by the stimulation of systemic inflammation by an underlying disease ${ }^{2}$. It is a multifactorial problem, involving both the disease and its associated factors and the problems resulting from hospitalization. Furthermore, malnutrition has a direct effect on the evolution of the disease, since it has consequences for different organs and systems, worsening the evolution of the patient, increasing morbidity and mortality, reducing their quality of life, and, as a consequence, increasing health expenditure ${ }^{4,5,6}$. The DRM affects 30 million people in Europe and involves 170 billion euros per year. In Spain, 1.7 million adults are at risk of malnutrition? ${ }^{7}$.

The Global Leadership Initiative on Malnutrition (GLIM) recently convened experts from leading clinical nutrition societies to standardize the definition of malnutrition and diagnostic criteria for malnutrition. They define undernutrition as: "phenotypic criterion (loss of body weight, low body mass index (BMI) or reduced muscle mass) associated with an etiological criterion (reduced food intake/assimilation or inflammation/burden of disease)" 8 .

$\mathrm{HM}$ has been a common problem for over 70 years. Currently, several studies show a prevalence in hospitalized patients of $30-50 \%$, however, this problem is not only frequent upon admission, but increases or starts during the hospital stay $9,10,11,12$. According to the study of prevalence of malnutrition and associated costs in Spain (PREDYCES), HM affects one in four patients (23\%) on hospital admission. This figure increases with age (37\% in those over 70 years, and $46-50 \%$ in those over 85 years), according to sex (women $25.7 \%$, men $20.7 \%$ ), in oncological patients (35\%), with cardiocirculatory diseases (29\%), respiratory diseases (28\%) and in hematological patients (36.8\%). In addition, the hospital stay of malnourished patients is longer than that of normal-nutrition patients (11.5 and 8.5 days, respectively), as is the hospital cost (12,237 euros versus 6,408 euros). The PREDYCES study concluded: "They are one in four, and cost $50 \%$ more" 5,13 .

The causes of DM are multifactorial, the disease that the patient suffers stands out, but it is also due to the decrease in the intake, the alteration of the metabolism, the appetite and the absorption of nutrients, the use of anorectic drugs, the increase in losses, the increase in both energy and protein requirements, and even in geriatric patients there are other factors such as dementia, immobilization or the lack of teeth, among others ${ }^{4,6}$.

Many times, on admission, patients already present malnutrition, this is mainly due to the disease they suffer, but, in addition, they can be derived from hospitalization, derived from medical teams or related to health authorities ${ }^{14}$.

When the nutritional status is deficient, the immune system, the gastrointestinal tract, the metabolic endocrine system and the cardiorespiratory function are affected, the healing process of the wounds is slowed down, the resistance of the surgical sutures is diminished, the risk of venous thrombosis is favoured by the rest, as well as the appearance of pressure ulcers and nosocomial infection, delaying recovery, prolonging hospital stays, increasing the rate of premature readmissions and significantly altering the individual's independence and quality of life, contributing to increased morbidity and negatively impacting on health $\operatorname{costs}^{13,15}$.

\section{Methods}


According to the definition of the glossary of terms in clinical malnutrition ${ }^{16}$, nutritional screening is: "the presumptive identification, in population groups, by means of rapid action tests, of subjects in a situation of malnutrition or who is at risk of altering their nutritional status, in order to act on them early". This is a preventive method, since it detects the risk of suffering from malnutrition. Even if the patients are pre-symptomatic, they may suffer from malnutrition in short period, so acting early and avoiding malnutrition is transcendental. The main objective of nutritional screening is: "to predict the likelihood of an unfavourable prognosis" and "to identify subjects who may benefit from nutritional treatment"17.

More specifically, in cancer patients, the importance of early detection of malnutrition, through appropriate screening implemented and validated in the hospital service, is reflected in facts such as that an early nutritional intervention could restore energy balance and improve the outcome of cachexia ${ }^{18}$.

\section{Nutritional Risk Screening_2002(NRS-2002):}

Nutritional screening system recommended by ESPEN for inpatients. First, an initial screening is performed, which consists of 4 questions that are answered with yes or no (TABLE 1) $19,20,21$.

According to the answers:

- If the answer is NO to all 4 questions, the test is repeated at weekly intervals.

- If the answer is YES to any of the questions, the screening in Table 2 is performed: the final screening test is completed, which assesses the nutritional status and severity of the disease (TABLE 2).

In the final screening test, the patient is classified according to nutritional status and severity of the disease, with each score from 0 to 3 , absent to severe, respectively. Both columns are then added together and a point is added if the patient is $>70$ years old. If the total sum is $>3$ points, there is nutritional risk, so nutritional support is necessary. On the other hand, if it is $<3$ points, since there is a probability of entering a risk situation throughout the admission, it is recommended to carry out the NRS-2002 weekly to avoid a case of malnutrition in the future.

The NRS-2002 screening test allows normonutrition patients to be discarded more quickly, as no anthropometric measurements are required, which is a great advantage. It is a test with high sensitivity, but low reproducibility ${ }^{13,21}$.

Although, according to another study, some other test such as PG-SGA seems more appropriate for identifying malnutrition in gynecological cancer patients ${ }^{22}$, our intention was to develop, validate and implement a screening tool throughout the oncohaematology service in a third level hospital, regardless of the type and location of the tumour.

\section{SAMPLE AND SAMPLING:}

The nutritional screening test NRS-2002 and NA was performed on 573 patients, with an inclusion period of one year (June 2017-August 2018), 372 men (64.92\%) and 201 women (35.08\%), with an average age of 59.46 years, ranging from a minimum of 16 years to a maximum of 93 years, and a median age of 61 years. The oncology and haematology service was chosen for the pioneering implementation of the nutritional screening test and therefore for the study, because patients admitted to these areas are at very high risk of suffering from malnutrition, both on admission and during their stay in hospital. In addition, they are patients with a high time of admission, so it is easier to observe their evolution.

With regard to this study, the NA was performed in all cases, independently of the nutritional screening test, in order to assess its usefulness, as well as its efficiency and effectiveness.

Firstly, the computer support was designed, using a clinical management system for hospital patients, Orion Clinic, specifically through direct access to the Dietetics programme created to carry out the nutritional screening test.

Once the nutritional screening is done, an alert is generated to the nutrition service by means of a list that indicates the test score corresponding to each patient.

\section{NUTRITIONAL SCREENING:}

The nutritional screening test is the NRS-2002.

If the final test is positive (>3 points), an alert will be generated to the hospital's nutrition service and the NA will be performed.

Through this assessment, malnutrition is diagnosed and classified according to its degree of severity.

Finally, when malnutrition is diagnosed, the doctor in charge and the nutrition and endocrinology service will be informed so that they can take the necessary measures to prevent or treat $\mathrm{HM}$.

\section{COMPLETE NUTRITIONAL ASSESSMENT:}

NA is performed when the nutritional screening test concludes that the patient is at risk of malnutrition or undernutrition. In this study, all patients are tested to ensure that the nutritional screening was performed correctly.

Page 3/9 
NA consists of anthropometric, biochemical, dietary, and clinical indicators of the patient.

Firstly, the personal data are completed, such as age, sex and the pathology he suffers from. These data are noted in the patient's medical history.

Secondly, the anthropometric assessment is performed, where we ask the usual weight; we weigh and measure the height, the triceps skinfold (TSF) and the mid-arm circumference (MAC); finally, we calculate the weight loss rate (WLR), the BMI and the mid-arm muscle circumference (MAMC).

Unintentional WLR as a form of nutritional depletion is commonly seen in aging, cancer, and many chronic diseases ${ }^{23}$.

Once all the data are complete, we compare the PT, CB and PMB data in the percentile table and observe in which percentile our patients are and, therefore, the type of malnutrition and protein depletion they suffer. In our study we measured body mass, height, TSF and MAC. With these data we have calculated the BMI and the MAMC with the International Society for the Advancement of Kinanthropometry method (ISAK) ${ }^{24}$.

The biochemical evaluation is extracted from the daily analyses carried out by the doctor in charge. Urine samples may offer a valid alternative or a complementary addition to serum for nutritional metabolism analyses in large-scale clinical and epidemiological studies ${ }^{25}$.

In our study we looked at creatinine, lymphocyte and glomerular filtrate data because they are the only nutritionally relevant data that appear in all daily analyses.

With regard to the dietary indicators, first of all, the type of diet is observed and a 24-hour record is made, asking the patient or the accompanying person how much food was ingested at each intake. The dietary indicators give information on both the amount of requirements covered and the composition of the diet. Something to keep in mind, since, for example, a lower intake of protein can be associated with more nausea ${ }^{26}$, and because although the foods consumed by patients with advanced cancer correspond largely to the typical foods consumed by healthy people ${ }^{27}$, it is the amounts that will determine to a greater extent the percentage of requirements covered.

The kilocalories and grams of protein of each intake are calculated and added up, calculating the total contribution in the diet. If the patient has any type of supplementation, either oral or by tube, the total intake is noted and calculated. The percentage of covered needs, both in terms of kilocalories and proteins, is then calculated using the following formula: (see Formula 1 in the Supplementary Files)

Finally, the clinical indicators, which are evaluated in a subjective way, either by observation or by asking the patients and, if this is not possible, their companions. In some of them, such as nausea, vomiting, diarrhea or constipation, if they answer yes, the number of times and the duration of these are further deepened; in the case of dysphagia, what texture is compromised.

\section{Results}

The agreement during visit 1 is moderate, with a value $k=0.57$, increasing progressively in visits 2,3 and 4 to considerable agreement, with $k$-values of 0.63 , 0.70 and 0.72 respectively (TABLE 3 ).

In our study we found that according to the nutritional screening test NRS-2002, 34.38\% were malnourished on hospital admission (197 patients), $44.68 \%$ at risk of malnutrition (256 patients) and only $20.94 \%$ in good nutritional condition (120 patients).

In addition, patients with longer admissions (>1 week) were re-evaluated weekly. $68.86 \%$ of patients maintained their nutritional status throughout their stay in hospital, with no improvement or worsening: they remained at normal nutritional status, risk of malnutrition and undernutrition from the time they were admitted to hospital $(7.38 \%, 31.97 \%$ and $29.51 \%$ respectively). On the other hand, $18.86 \%$ of patients improve their nutritional status upon discharge from hospital: they go from risk of malnutrition to normonutrition and from malnourished to risk of malnutrition ( $7.38 \%$ and $11.48 \%$ respectively). Finally, $12.3 \%$ of patients worsen their nutritional status during their stay in hospital: they go from normonutrient to risk of malnutrition and from risk of malnutrition to malnourished $(7.38 \%$ and $4.92 \%$ respectively).

It can be seen that, of the $68.86 \%$ of patients who maintain their nutritional status, $61.48 \%$ are at risk of malnutrition or undernutrition, requiring a NA. If we add to this the $12.3 \%$ of patients who worsen their nutritional status during their hospital stay, we conclude that $73.78 \%$ of the total patients who are admitted to hospital for more than one week require a NA, and, if necessary, extra nutritional support.

We can see that, at hospital discharge, $34.43 \%$ are malnourished, $50.83 \%$ at risk of malnutrition and $14.76 \%$ with good nutritional status, so that $85.26 \%$ of patients need some kind of extra nutritional support.

If we apply the GLIM criteria, we have found that $100 \%$ of the patients present an inflammatory load due to the tumour disease they suffer, as well as $26 \%$ of the patients ingest $\leq 50 \%$ of the energy requirements for $>1$ week and $82.4 \%$ of the patients ingest $\leq 100 \%$ of the requirements for $>2$ weeks. $100 \%$ of patients meet at least 1 aetiological criterion. On the other hand, with regard to the phenotypical criteria, $55.1 \%$ of the patients present a weight loss greater than $5 \%, 23.4 \%$ of the patients present $\mathrm{BMI}<20 \mathrm{Kg} / \mathrm{m}^{2}$ and $54 \%$ of the patients with admissions greater than a week's duration present a decrease in muscle mass measured by the MAMC. $72.3 \%$ of the patients present at least 1 phenotypic criterion and $100 \%$ of the patients present at least 1 etiological criterion, so it is concluded that $72.3 \%$ of the patients studied present malnutrition according to GLIM criteria.

\section{Discussion}


Gutiérrez et al. conducted a study with a sample of 247 patients hospitalized in a second level hospital, finding that $42 \%$ of the patients were at risk of malnutrition in the first 24 hours after admission. In addition, they concluded that there was a significant association between nutritional risk and decreased food intake in the last week, as well as severity of illness, age and gender. On the other hand, a decrease in food intake increased the probability of presenting a nutritional risk by 6.67 times $^{28}$.

Barbosa et al. concluded that $46.4 \%$ of the 763 patients studied were at nutritional risk, with greater possibilities in men and the elderly. In addition, BMI $<20.5 \mathrm{~kg} / \mathrm{m}^{2}$ and WLR in the last 3 months were the most important factors contributing to the determination of nutritional risk ${ }^{29}$.

Burgos et al. compared the risk of malnutrition results obtained by the NRS-2002 screening test and the Mini Nutritional Assessment (MNA) in 101 chronic patients with complex hospital needs. They found that $83 \%$ of these patients were malnourished or at risk of malnutrition according to the NRS-2002 and $86 \%$ according to the MNA. In addition, they found that malnourished patients had greater home care needs and higher mortality rates during admission and at 5 months after assessment. The factors most strongly associated with malnutrition were BMI and female sex ${ }^{30}$.

Ying et al. detected the nutritional risk on hospital admission of 745 elderly patients using the NRS-2002 and MNA nutritional screening test, obtaining a $39.81 \%$ and $44.10 \%$ risk of malnutrition respectively. Specifically, according to NRS-2002, $33.38 \%$ of patients were at risk of malnutrition and $6.43 \%$ were malnourished. The incidence of risk of malnutrition in gastroenterology, hematology and respiratory services was $51.72 \%, 46.88 \%$ and $43.33 \%$, respectively, higher than in other services. It concluded that patients at nutritional risk were more likely to have high hospital stays, and that malnourished or at-risk patients who received extra nutritional support had shorter hospital stays and fewer infectious complications than patients without extra ${ }^{\text {nutritional }}$ support ${ }^{31}$.

Miao et al. compared the risk of malnutrition obtained through the NRS- 2002 nutritional screening test and the MNA in 425 elderly patients, with an age range of 70 to 98 years and an average age of $81.2 \pm 5.9$ years, finding that the prevalence of malnutrition through the first test was $40.9 \%$ and the second test 58.6\%. Malnourished patients had lower BMI, haemoglobin, albumin and prealbumin. In addition, it concluded that both nutritional screening tests showed a significant correlation with age, BMI and analytical parameters, as well as a significant association between both tools ${ }^{32}$.

Álvarez et al. conducted a study with 444 cancer patients, presenting $50.2 \%$ of the same nutritional risks. The factors most associated with this risk were male gender, age, $\mathrm{BMI}<20.5$, weight loss, poor food intake and hematological tumors ${ }^{33}$.

Müller et al. studied all patients admitted for 12 months to the nephrology service of the University Hospital of Bern Inselspital, Switzerland, specifically 696 patients. They found that $35.6 \%$ of them were at risk of malnutrition, as well as a significant association between an NRS-2002 result $>3$ and higher hospital mortality, and the risk of malnutrition with longer hospital stay and higher hospitalization $\operatorname{costs}^{34}$.

García et al. carried out a study using the implementation of the NRS-2002 nutritional screening test. In the implementation phase, they studied 1123 patients, finding that $19 \%$ were at risk of malnutrition according to the nutritional screening test. Of these, $77 \%$ were $>70$ years old. $27 \%$ had higher scores in the section on alteration of nutritional status, $27 \%$ in the section on severity of disease and $40 \%$ in both sections equally. $25 \%$ of the patients at risk according to the NRS-2002 were readmitted in less than 30 days and the mortality rate was $5 \%$. On the other hand, in the consolidation phase, they studied 2527 patients: $15 \%$ were at nutritional risk. $73 \%$ were $>70$ years old ${ }^{35}$.

Stollhof et al. examined 1372 hospitalized patients using the NRS-2002 screening test, concluding that $51 \%$ of patients were at risk of malnutrition. Differentiating according to the services studied, it was found that $62 \%$ of patients in septic surgery were malnourished, $41 \%$ of patients in traumatology and $58 \%$ of patients in arthroplasty. Moreover, this study finds the additional economic cost of a patient with poor nutritional status to public spending, calculating a total of $290,207.17 €$ in 2 years of the study, specifically for each male patient was calculated a cost of $7768 €$, which increased to $7849.72 €$ after detecting malnutrition (NRS $\geq 3)^{36}$.

Yuan et al. evaluated 1664 patients with metastatic gastric cancer using the NRS-2002 test, finding that a value $>3$ in the test is associated with greater postoperative morbidity, higher mortality and shorter progression-free survival than those patients who obtained $<3$ in the nutritional screening test. In addition, patients with $a>3$ value tended to have lower serum albumin and less first-line chemotherapy (CT) $)^{37}$.

Chivu et al. studied at the University General Hospital of Valencia, a tertiary hospital in the Valencian Community, the detection of malnutrition using the Hospital Malnutrition Assessment Tool (HEMAN), which is an unvalidated nutritional screening test. It was found that $33.5 \%$ of the patients were at risk of malnutrition. Patients with a positive nutritional screening test were older than normonutrient patients and their body weight decreased by $5-10 \%$. $55.2 \%$ of the patients decreased $>50 \%$ of their usual intake ${ }^{21}$.

The MNA nutritional screening test is validated in a geriatric population. As explained above, Miao et al. after comparing the NRS-2002 and MNA nutritional screening tests found that the latter obtained a prevalence of $58.6 \%$ of malnutrition in elderly patients admitted to 8 medical centres in Hubei, China ${ }^{32}$.

Guigoz conducted a literature review of 21 studies, estimating malnutrition in hospitalized elderly patients using the MNA test, concluding that $46 \%$ were at risk of malnutrition and $23 \%$ were malnourished ${ }^{38}$. Likewise, Sanz et al. reviewed the results obtained in 35 Spanish hospitals, which used the same nutritional screening test, detecting that $39.1 \%$ were at risk of malnutrition and $21.2 \%$ were malnourished $^{39}$.

On the other hand, the Global Subjective Assessment method (GSA) was also used by Moriana et al. to detect malnutrition in a third-grade hospital in Valencia, obtaining that $50 \%$ of the 197 patients studied were malnourished. The average stay of malnourished patients was longer than that of patients at 
risk of malnutrition and normonutrients, 13.5, 12.1 and 6.97 days respectively. The GSA correlated significantly with anthropometric and biochemical parameters of malnutrition 40 .

Sremanakova et al. assessed the risk of malnutrition in 727 patients hospitalized after a stroke using the MUST screening test, of the 1101 admitted to this service, meaning that only $66 \%$ of the patients were examined. Of these, $78.5 \%$ were at low risk of malnutrition, while $4.1 \%$ and $17.4 \%$ were at medium or high risk of malnutrition, respectively, which adds up to $21.5 \%$ of patients at medium to high risk of malnutrition and who should be monitored nutritionally, as they are more likely to have longer hospital stays and a higher risk of mortality ( $10.9 \%$ and $3.5 \%$, respectively). Significantly, and despite the low prevalence of risk of malnutrition in these patients, almost $1 / 3$ of the patients were not evaluated ${ }^{4}$.

Almasaudi et al. studied 363 patients undergoing surgery for colorectal cancer, assessing their nutritional status by means of the MUST test. The $21 \%$ of the patients presented medium-high nutritional risk. They found significant associations between the MUST test and subcutaneous adiposity, visceral obesity and skeletal muscle index. As well as longer hospital stay and shorter survival ${ }^{42}$.

For all these reasons, the importance of implementing a nutritional screening test that detects the DRM early when the patient is admitted to hospital has been sufficiently demonstrated.

As far as we know, our study is the first to show that the NRS-2002 nutritional screening test is a useful, valid and highly applicable tool for the early detection of malnutrition and, therefore, to act quickly, avoiding possible complications in an oncohaematology service in a third level hospital.

\section{Conclusions}

1. Nutritional screening based on the Nutritional Risk Screening 2002 (NRS-2002) presents better concordance analysis as the number of patient reevaluations increases.

2. According to the Nutritional Risk Screening 2002 (NRS-2002) method, 34.4\% of patients admitted to the oncohematology service of the Hospital Politécnico La Fe present malnutrition, $44.7 \%$ risk of malnutrition and $20.9 \%$ of the patients studied present normonutrition.

3. $3 \%$ of patients with admissions of more than one week worsen their nutritional status, $68.9 \%$ maintain it and only $18.9 \%$ improve it. $78.8 \%$ of patients with longer admissions require a complete nutritional assessment.

4. At hospital discharge, $34.4 \%$ of patients are malnourished, $50.8 \%$ are at risk of malnutrition and only $14.8 \%$ are in good nutritional condition.

5. Nutritional Risk Screening 2002 (NRS-2002) is a suitable method for the early detection of malnutrition in the patient hospitalized in an oncohematology unit. Due to the profile of the patient by their average age, as well as the profile of the center and service where they are institutionalized.

\section{Abbreviations}

BMI: Body Mass Index; DRM: Disease Related Malnutrition; GLIM: Global Leadership Initiative on Malnutrition; HM: hospital malnutrition; MAC: mid-arm circumference; MAMC: mid-arm muscle circumference; NA: complete nutritional assessment; NRS-2002: Nutritional Risk Screening 2002; PREDYCES: study of the prevalence of malnutrition and associated costs in Spain; TSF: triceps skinfold; WLR: weight loss rate.

\section{Declarations}

Ethical Approval and Consent to participate: Informed consent was obtained from all participants after being informed about the aim of the study, risks, and implications of their participation in it, as well as the treatment and confidentiality of the data. This study was approved by the Biomedical Research Ethics Committee of University and Polytechnic Hospital La Fe, respecting the fundamental principles of the Declaration of Helsinki, of the Council of Europe Convention in relation to Human Rights and Biomedicine of the UNESCO Declaration.

Consent for publication: yes

Availability of supporting data: yes

Competing interest: not applicable

Funding: not applicable

Authors' contributions: Conceptualization, methodology, formal analysis, data curation and writing: Marta Pérez, José M Soriano, Juan F Merino-Torres. Investigation and writing (original draft preparation and writing): Marta Pérez. Project administration: Juan F Merino-Torres.

Acknowledgements: to thank the oncohematology service of Hospital La Fe for their participation in the study and the support provided.

Authors' information: Marta Pérez MSC, José M Soriano M.D., J. Francisco Merino-Torres Ph.D.

\section{References}


1. Abroix M. (2006). Desnutrición hospitalaria. [Consultado el 2 de febrero de 2017). Disponible en: http://www.consumer.es/web/es/salud/atencion_sanitaria/2006/05/26/152406.php.

2. Cederholm T, Barazzoni R, Austin P, et al. (2017). ESPEN guidelines on definitions and terminology of clinical nutrition. Clinical Nutrition. 36:49-64.

3. Buijs N, Van Bokhorst M, Langius J, et al. (2010). Perioperative arginine-supplemented nutrition in malnourished patients with head and neck cancer improves long-term survival. The American Journal of Clinical Nutrition. 92:1151-1156.

4. Palma S, Meneses D, Valero M, et al. (2018). Costes asociados a la desnutrición relacionada con la enfermedad y su tratamiento: revisión de la literatura. Nutrición Hospitalaria. 35:442-460.

5. Álvarez J, Planas M, León M, et al. (2012). Prevalence and costs of malnutrition in hospitalized patients; The PREDyCES® Study. Nutrición Hospitalaria. 27:1049-1059.

6. Burgos R. (2013). Desnutrición y enfermedad. Nutrición Hospitalaria. 6:10-23.

7. $3^{\mathrm{a}}$ conferencia de la Optimal Nutrional Care For All. Alianza masnutridos 2016. [Consultado: 9 de marzo de 2016]. Disponible en: http://www.alianzamasnutridos.es/news/1,7\%20millones\%20de\%20adultos\%20en\%20Espa\%C3\%B1a,\%20en\%20riesgo\%20de\%20desnutrici\%C3\%B3n/

8. Cederholm T, Jensen GL, Correia M, et al. (2019). GLIM criteria for the diagnosis of malnutrition - A consensus report from the global clinical nutrition community. Clinical Nutrition. 38:1-9.

9. García A, Álvarez J y Calvo MV. (2005). “Conclusiones del II Foro de Debate SENPE sobre desnutrición hospitalaria”. Nutrición Hospitalaria. $20: 82-87$.

10. Álvarez J, Del rio J, Planas M, et al. (2008). Documento SENPE-SEDOM sobre la codificación de la desnutrición hospitalaria. Nutrición Hospitalaria. 23:536-540.

11. Waitzberg DL, Ravacci GR y Raslan M. (2011). Desnutrición hospitalaria. Nutrición hospitalaria: Órgano oficial de la Sociedad española de nutrición parenteral y enteral. Nutrición Hospitalaria. 26:254-264.

12. Gordon L, Jensen HL, Compher C, et al. (2013). Recognizing Malnutrition in Adults: definitions and Characteristics, Screening, Assessment and Team Aproach. Journal of Parenteral and Enteral Nutrition. 37: 802-807.

13. (2011). Consenso Multidisciplinar sobre el abordaje de la desnutrición hospitalaria en España. Promovido por la Sociedad Española de Nutrición Parenteral y Enteral (SENPE). Barcelona: Editorial Glosa, S.L.

14. Lecha M y Ribot I. (2011). Desnutrición hospitalaria. Nutrición Hospitalaria. 26:1-36.

15. Ulibarri Jl, Picón MJ, García E, et al. (2002). Early detection and control of hospital malnutrition. Nutrición Hospitalaria. 17:39-146.

16. Glosario de términos en desnutrición clínica. (2013). [Consultado: 2 de febrero del 2020]. Disponible: https://controlnutricional.files.wordpress.com/2010/12/glosario-de-terminos-en-desnutricion-clinica.pdf

17. Ulibarri JI. (2018). Cribado nutricional y eficiencia. Nutrición Hospitalaria. 1:1001-1002.

18. Vazeille C, Jouinot A, Durand JP, et al. (2017). Relation between hypermetabolism, cachexia, and survival in cancer patients: a prospective study in 390 cancer patients before initiation of anticancer therapy. The American Journal of Clinical Nutrition.105:1139-1147.

19. Kondrup J, Allison S y Elia M. (2003a). ESPEN Guidelines for Nutrition Screening 2002. Clinical Nutrition. 22:415-421

20. Kondrup J, Rasmussen H y Hamberg O. (2003b). Nutritional risk screening (NRS 2002): a new method based on an analysis of controlled clinical trials. Clinical Nutrition. 22:321-336.

21. Chivu EC, Artero A, García A, et al. (2016). Detection of malnutrition risk in hospital. Nutrición Hospitalaria. 33:894-900.

22. Laky B, Janda M, Cleghorn G, et al. (2008). Comparison of different nutritional assessments and body-composition measurements in detecting malnutrition among gynecologic cancer patients. The American Journal of Clinical Nutrition. 87:1678-1685.

23. Miller J, Wells L, Nwulu U, et al. (2018). Validated screening tools for the assessment of cachexia, sarcopenia, and malnutrition: a systematic review. The American Journal of Clinical Nutrition. 108:1196-1208.

24. Stewart A, Marfell M, Olds T, et al. (2011). Protocolo internacional para la valoración antropométrica. Sociedad internacional para el avance de la Cineantropometría (ISAK). Portsmouth: ISAK.

25. Playdon MC, Sampson JN, Cross AJ, et al. (2016). Comparing metabolite profiles of habitual diet in serum and urine. The American Journal of Clinical Nutrition. 104:776-789.

26. Yeung SE, Hilkewich L, Gillis C, et al. (2017). Protein intakes are associated with reduced length of stay: a comparison between Enhanced Recovery After Surgery (ERAS) and conventional care after elective colorectal surgery. The American Journal of Clinical Nutrition. 106:44-51.

27. Hutton J, Martin L, Field C, et al. (2006). Dietary patterns in patients with advanced cancer: implications for anorexia-cachexia therapy. The American Journal of Clinical Nutrition. 84: 1163-1170.

28. Gutiérrez JL, Aguilar S, Casas M, et al. (2019). Screening of nutritional risk: assessment of predictive variables of nutritional risk in hospitalized patients in a second-level care center in Mexico. Nutrición Hospitalaria. 36:626-632.

29. Barbosa AAO, Pereira A y Ramos F. (2019). Comparação dos critérios da nrs-2002 com o risco nutricional em pacientes hospitalizados. Ciência \& Saúde Coletiva. 24:3325-3334.

30. Burgos R, Joaquin C, Blay C, et al. (2019). Disease-related malnutrition in hospitalized chronic patients with complex needs. Clinical Nutrition. 1:15321983.

31. Ying L, Min W, Nuan S, et al. (2019). Screening and application of nutritional support in elderly hospitalized patients of a tertiary care hospital in China. Public Library of Science. 14:213-276. 
32. Miao J, Quan X, Zhang C, et al. (2019). Comparison of two malnutrition risk screening tools with nutritional biochemical parameters, BMI and length of stay in Chinese geriatric inpatients: a multicenter, cross-sectional study. British Medical Journal. 9:229-293.

33. Álvarez K, Delgadillo T, García A, et al. (2014). Prevalencia de riesgo de desnutrición evaluada con NRS-2002 en población oncológica Mexicana. Nutrición Hospitalaria. 30:173-178.

34. Müller M, Dahal S, Saffarini M, et al. (2019). Evaluation of Nutrition Risk Screening Score 2002 (NRS) assessment in hospitalized chronic kidney disease patient. Public Library of Science. 14:200-211.

35. García P, Velasco C, Frias L, et al. (2019). Protocolo de implantación de un cribado para la detección precoz del riesgo nutricional en un hospital universitario. Journal of Endocrinology, Diabetes and Nutrition. 66:555-562.

36. Stollhof L, Braun J, Ihle C, et al. (2019). The continuous downgrading of malnutrition in the German DRG system: possible effects on the treatment of patients at risk for malnutrition. Experimental and Clinical Sciences. 18:370-381.

37. Yuan L, Run N, Tink W, et al. (2019). Prognostic Value of the Nutritional Risk Screening 2002 Scale in Metastatic Gastric Cancer: A Large-Scale Cohort Study. Journal of Cancer. 10:112-119.

38. Guigoz Y. (2006). The Mini-Nutritional Assessment (MNA®) Review of the Literature - What does it tell us?. The Journal of Nutrition, Health \& Aging. 10:466-487.

39. Sanz A, García JM, Gómez-Candela C, et al. (2013). Malnutrition prevalence in hospitalized elderly diabetic patients. Nutrición Hospitalaria. 28:592-599.

40. Moriana M, Civera M, Artero A, et al. (2014). Validez de la valoración subjetiva global como método de despistaje de desnutrición hospitalaria. Prevalencia de desnutrición en un hospital terciario. Endocrinología y Nutrición. 61:184-189.

41. Sremanakova J, Burden S, Kama Y, et al. (2019). An Observational Cohort Study Investigating Risk of Malnutrition Using the Malnutrition Universal Screening Tool in Patients with Stroke. Journal of Stroke and Cerebrovascular Diseases. 27:104-405.

42. Almasaudi A, McSorley S, Dolan R, et al. (2019). The relation between Malnutrition Universal Screening Tool (MUST), computed tomography-derived body composition, systemic inflammation, and clinical outcomes in patients undergoing surgery for colorectal cancer. The American Journal of Clinical Nutrition. 1:2-30.

\section{Tables}

TABLE 1: NUTRITIONAL RISK SCREENING 2002: initial screening

\begin{tabular}{|c|l|c|c|}
\hline 1 & Is BMI <20,5\%? & Yes & No \\
\hline 2 & Has the patient lost weight within the last 3 months? & Yes & No \\
\hline 3 & Has the patient had a reduced dietary intake in the last week? & Yes & No \\
\hline 4 & Is the patient severely ill? & Yes & No \\
\hline
\end{tabular}

TABLE 2: NUTRITIONAL RISK SCREENING 2002: final screening

\begin{tabular}{|c|c|c|c|}
\hline \multicolumn{2}{|r|}{ NUTRITIONAL STATUS } & \multicolumn{2}{|r|}{ DISEASE SEVERITY } \\
\hline $\begin{array}{l}\text { Absent } \\
0 \text { points }\end{array}$ & Normal nutritional status & $\begin{array}{l}\text { Absent } \\
0 \text { points }\end{array}$ & Normal nutritional requirements \\
\hline $\begin{array}{l}\text { Mild } \\
1 \text { point }\end{array}$ & $\begin{array}{l}\text { Weight loss }>5 \% \text { in } 3 \text { months or food intake }<50-75 \% \text { of normal requirement in } \\
\text { previous week }\end{array}$ & $\begin{array}{l}\text { Mild } \\
1 \text { point }\end{array}$ & $\begin{array}{l}\text { Hip fracture, Chronic patients, in particular with acute } \\
\text { complications: cirrhosis, COPD. Chronic hemodialysis, diabetes, } \\
\text { oncology }\end{array}$ \\
\hline $\begin{array}{l}\text { Moderate } \\
2 \text { points }\end{array}$ & $\begin{array}{l}\text { Weight loss }>5 \% \text { in } 2 \text { months or BMI } 18.5-20.5+\text { impaired general condition or } \\
\text { food intake } 25-60 \% \text { of normal requirement in previous week }\end{array}$ & $\begin{array}{l}\text { Moderate } \\
2 \text { points }\end{array}$ & $\begin{array}{l}\text { Major abdominal surgery, STROKE, severe pneumonia, } \\
\text { hematological tumors }\end{array}$ \\
\hline $\begin{array}{l}\text { Severe } \\
3 \text { points }\end{array}$ & $\begin{array}{l}\text { Weight loss }>5 \% \text { in } 1 \text { month ( }>15 \% \text { in } 3 \text { months) or BMI }<18.5+\text { impaired general } \\
\text { condition or food intake } 0-25 \% \text { of normal requirement in previous week }\end{array}$ & $\begin{array}{l}\text { Severe } \\
3 \text { points }\end{array}$ & $\begin{array}{l}\text { Head injury, bone marrow transplant, intensive care patients } \\
\text { (APACHE }>10 \text { ) }\end{array}$ \\
\hline \multicolumn{2}{|l|}{ Score $=$} & \multicolumn{2}{|l|}{ Score $=$} \\
\hline \multicolumn{4}{|c|}{ Age: if $>70$ years: add 1 to total score } \\
\hline
\end{tabular}

TABLE 3: Concordance Analysis Summary. 


\begin{tabular}{|l|l|}
\hline VISIT & KAPPA VALUE \\
\hline 1 & 0.57 \\
\hline 2 & 0.63 \\
\hline 3 & 0.70 \\
\hline 4 & 0.72 \\
\hline
\end{tabular}

\section{Supplementary Files}

This is a list of supplementary files associated with this preprint. Click to download.

- Formula1.pdf 